\title{
Insidious Dangers of Benevolent Sexism: Consequences for Women's Performance
}

\author{
Benoit Dardenne \\ University of Liège
}

\author{
Muriel Dumont \\ University of Liège and Catholic University of Louvain
}

\author{
Thierry Bollier \\ University of Liège
}

\begin{abstract}
Four experiments found benevolent sexism to be worse than hostile sexism for women's cognitive performance. Experiments 1-2 showed effects of paternalist benevolent sexism and ruled out explanations of perceived sexism, context pleasantness, and performance motivation. Experiment 3 showed effects of both paternalist and complementary gender differentiation components of benevolent sexism. Benevolent sexism per se (rather than the provision of unsolicited help involved in paternalism) worsened performance. Experiment 4 showed that impaired performance due to benevolent sexism was fully mediated by the mental intrusions women experienced about their sense of competence. Additionally, Experiment 4 showed that gender identification protected against hostile but not benevolent sexism. Despite the apparently positive and inoffensive tone of benevolent sexism, our research emphasizes its insidious dangers.
\end{abstract}

Keywords: benevolent and hostile sexism, discrimination, performance and working memory, ingroup identification, sense of competence

Sexism is expressed in a variety of ways, some more subtle than others and some more hostile than others. Examples of this attitude are gender-related humor, sexist name-calling, sexual harassment, and employment discrimination. Gender discrimination, like any other type of discrimination, is less and less accepted in our modern societies, and legislation has been designed to promote gender equality. In Europe, for instance, Article 141 of the European Commission's treaty states that any job classification system that is used for determining pay must be based on the same criteria for both men and women and be so written as to exclude any sex discrimination. Nonetheless, even if obvious forms of sexism are often socially condemned, more subtle forms of sexism are not. Worse, they sometimes are promoted, as they may sound positive in tone or even seem gallant or chivalrous. Consider, for instance,

Benoit Dardenne and Thierry Bollier, Department of Cognitive Sciences, University of Liège, Liège, Belgium; Muriel Dumont, Department of Cognitive Sciences, University of Liège, and Catholic University of Louvain, Belgium.

This research was supported by an incentive grant I-06/07 from the University of Liège, Belgium, to Benoit Dardenne. We are very grateful to Susan T. Fiske for her valuable help.

Correspondence concerning this article should be addressed to Benoit Dardenne, Department of Cognitive Sciences, University of Liège, Boulevard du Rectorat 5, B-32, B-4000, Liège, Belgium. E-mail: b.dardenne@ulg.ac.be a man helping a woman to carry luggage, paying for her meal at a restaurant, or complimenting her caring abilities. One might ask what is wrong with that. The problem is that people do not notice that these behaviors may be threatening. These kinds of behavior might, however, be expressions of paternalism or else might ambivalently flatter women while simultaneously implicitly suggesting their inferiority. Paternalism suggests that men should take responsibility for the welfare of women, who might not be able to carry luggage by themselves, might not earn enough money to pay at the restaurant, and should be remembered for their qualities (warmth) rather than their weak points (competence). In this article, we propose that paternalism as well as the other aspects of benevolent sexism, by suggesting women's lack of ability, are devastating to women's performance.

\section{Sexism Versus Patronizing}

Hostile and benevolent sexism often go hand in hand and result in ambivalent attitudes toward women (Glick \& Fiske, 1996, 2001). Hostile sexism is an obviously antagonistic attitude toward women, who are often viewed as trying to control men through feminist ideology or sexual seduction. Benevolent sexism, on the other hand, is a more positive attitude (often paternalistic, but not necessarily) toward women that appears favorable but is actually sexist because it portrays women as warm but incompetent or weak individuals in need of men's protection and support. Sexism 
thus prescribes how roles and relationships between men and women are or should be, suggesting the superiority of men over women. Glick and Fiske (1996) developed the Ambivalent Sexism Inventory (ASI) to tap the ambivalence manifested through the combination of these two aspects involved in sexism, and they conceptually distinguished the two subcomponents.

Benevolent sexism overlaps with patronizing behavior. Patronizing is acting and treating others in a condescending manner, thereby suggesting the patronizing person's personal superiority or the other person's inferiority. When enacted by a man toward a woman, patronizing thus resembles sexism because one person or category of persons is thought to be superior to another.

In a recent study, Vescio, Gervais, Snyder, and Hoover (2005) investigated the consequences that patronizing behavior of the powerful has on women's performance in stereotype-relevant domains. They examined the simultaneously inequitable and patronizing behavior of powerful men toward their subordinates. After women were praised for their work but assigned a devalued rather than a valued position, their performance decreased, but men's performance increased on a subsequent masculine task (i.e., a leadership task implying strong strategic, planning, and competitive skills). The argument that the authors developed was that patronizing behavior was perceived as unfair and elicited anger among subordinates who received simultaneous praise and devalued position assignments. However, men seemed to consider performance as a way to fight the initial injustice, whereas women did not. Indeed, anger in such a patronized condition was positively correlated with men's performance but was uncorrelated with women's performance. This was presumably the case because women did not see performance of the masculine task as being a possible way to eliminate anger in that setting (see Harmon-Jones, Sigelman, Bohling, \& Harmon-Jones, 2003).

Importantly, however, nothing could be concluded about the mechanisms leading women to perform worse under patronizing behavior, except that anger did not cause the decrease. Rather, Vescio et al. (2005) suggested that women might doubt their capacity to challenge the initial unfair position assignment. Indeed, they had poor performance expectations; they felt less confidence and personal control than did men in such a stereotype-relevant domain, even before the manipulation. Because they might not feel that they had the resources to cope with patronizing behavior, women perhaps experienced a sort of "learned helplessness," which would be responsible for their performing badly (Vescio et al., 2005). Unfortunately, such an alleged process was not examined directly.

Patronizing, as operationalized by Vescio et al. (2005), is a form of paternalist sexism involving both a positive side (praising) and a negative side (devalued position assignment), the latter suggesting women's alleged incompetence. Ambivalence is as present in patronizing behavior as it is in benevolent sexism. Indeed, benevolent sexism is a chivalrous attitude toward women that nevertheless is sexist by praising women on characteristics usually associated with subordinates and suggesting their dependence on men. However, although women's inferiority is implicitly suggested through benevolent sexism and often not even noticed by women themselves (Barreto \& Ellemers, 2005), patronizing involves a component of obvious discrimination, or at least obviously unfair behavior, suggesting women's alleged lack of ability. Hostile sexism similarly explicitly communicates men's negative view of women. Patronizing is thus perhaps closer to hostile sexism in its explicit discriminatory character. In our view, Vescio et al.'s (2005) patronizing behavior might thus be conceived as Glick and Fiske's $(1996,2001)$ overall ambivalent sexism, which reveals itself through both hostile and benevolent sexist attitudes.

However, research has shown that hostile and benevolent sexism, though correlated, predict different values (Abrams, Viki, Masser, \& Bohner, 2003; Ford, Wentzel, \& Lorion, 2001; Sakalli \& Glick, 2003; Viki \& Abrams, 2003). Our aim in this article was to determine the specific consequences that hostile and benevolent sexism each have on the performance of women. Also, we examined the specific processes that are associated with each form of sexism. That is, we considered anger and motivation to perform on the one hand and helplessness or self-doubt on the other hand. Moreover, in order to fully appreciate sexism's impact on the performance of women and to preclude the context of a masculine domain to be the source of self-doubt, threat, or feelings of helplessness, we considered the context of a feminine domain instead, in which there are no stereotype-based lower expectancies for women than for men.

\section{Why Would Hostile and Benevolent Sexism Differ in Their Consequences for Performance and Associated Processes?}

One possibility is that hostile sexism, because of the explicit discrimination it suggests, would be identified as sexism, so hostile sexism would elicit anger and increased motivation to perform. On the other hand, benevolent sexism, being more subtle and sweet and implicitly suggesting women's lack of abilities, would not be characterized as sexism and would not elicit as much motivation to perform as hostile sexism would. Indeed, according to appraisal theories of emotion, anger is most often elicited when people appraise their situation as unfair and due to another person's agency (Frijda, Kuipers, \& ter Schure, 1989; Scherer, 1988; Smith \& Ellsworth, 1985). Along similar lines, reactance theory (Brehm, 1966; Brehm \& Weintraub, 1977) proposed that when a restriction is seen as unfair, people get an unpleasant feeling called reactance. This is an intense motivational state that results in people feeling that they must do something to get around the restriction. Increased motivation to perform and better performance would actually be means to override the initial unfair expression of sexism. Appraising the situation as unfair - that is, identifying sexism as suchwould be a prerequisite for experiencing anger and increased motivation to perform. Although we believed that benevolent sexism would not be identified as sexism, women might nevertheless perceive the situation as unpleasant and react angrily to it. Therefore, we doubted that hostile and benevolent sexism would differ in their capacity to elicit a motivation to perform.

Alternatively, we propose another mechanism by which sexism might affect women's performance. A considerable body of research has suggested that activating group stereotypes or traits leads to behaviors that conform to these constructs. For instance, activating the concept of professors or thinking of oneself as being a professor, even if role-played, has led people to become contextually smarter, whereas activating the concept of the elderly led people to become forgetful (e.g., Bargh, 1997; Chen \& Bargh, 1997; Dijksterhuis, Aarts, Bargh, \& van Knippenberg, 2000; Dijksterhuis \& van Knippenberg, 1998; see Dijksterhuis \& Bargh, 2001; Wheeler \& Petty, 2001, for recent reviews). Implicitly 
suggesting that women lack abilities through benevolent sexism should then similarly lead women to perform badly. On the other hand, hostile sexism (which suggests that women are mean and disliked by men but does not imply their lack of competence) should not elicit poor performance.

Another cognitive process that is complementary rather than incompatible with the automatic behavior research just mentioned also provides an interesting explanation. Because benevolent sexism implicitly suggests women's lack of competence but provides ambivalent feelings due to the praise it simultaneously involves, such a subtle form of sexism might lead women to doubt their abilities to perform well. This assumes that although benevolent sexism would be subtle enough not to be identified as sexism, women confronted with such sexism would nevertheless experience benevolent comments as quite unpleasant. The implicit suggestion that women lack ability would then lead women to doubt their capacities and experience a decrease in self-esteem and self-confidence as well as to feel preoccupied during their tasks. This would definitely impair their performance. In contrast, hostile sexism would generate much less intrusive thought, because hostility is explicitly manifested and external. Indeed, contrary to benevolent sexism, hostile sexism leaves no ambiguity as to the opinion of those who express it. Unpleasant feelings might thus easily be attributed to the speaker's sexism. In contrast, when inferiority of women compared with men is suggested implicitly and accompanied by praise, whatever happens in the situation cannot easily be attributed to the person expressing benevolence. We thus proposed that benevolent sexism triggers self-doubt among women. Such doubts and other intrusive thoughts then disturb performance, especially when tasks require working memory capacity.

Working memory is involved in many daily activities; for instance, when people have to do several tasks simultaneously or when they have to concentrate on a resource-consuming task. Working memory focuses attention on temporarily activated information necessary for the task at hand (e.g., writing good arguments) while inhibiting irrelevant information (e.g., one's colleagues' discussion about a movie; Engle, 2001; Engle, Tuholski, Laughlin, \& Conway, 1999). In a test situation, working memory should hold the data necessary to solve the problem and, at the same time, suppress task-irrelevant information. Schmader and Johns (2003), for instance, found that the threat elicited by the salience of a negative stereotype reduced women's math performance by diminishing working memory. We suggested that benevolent sexism would trigger intrusive thoughts that would similarly interfere with performance by reducing working memory capacity. Indeed, one part of the available working memory resources would be devoted to manage self-doubt and intrusive thoughts, rather than be fully allocated to performing the task. In sum, benevolent but not hostile sexism should increase "mental intrusions," such as unwanted thoughts related to self-doubt, anxiety, preoccupation, or threatened sense of competence (e.g., Beilock \& Carr, 2005; Beilock, Kulp, Holt, \& Carr, 2004), which should impair women's working memory capacity and decrease their performance.

\section{Variables Potentially Protecting Against Sexism}

Sexism conveys attitudes about women. Therefore, gender identification might well moderate the effects of sexism on mental intrusions and performance. Indeed, there are individual differ- ences in the tendency to detect discrimination (e.g., Stangor et al., 2003). Some women more strongly identify with their gender group and have a better constructed and more positive image of their ingroup than other women. The former may actually be better able than the latter to detect and blame discrimination in a primary appraisal. In a secondary appraisal, women who identify strongly could then more easily disregard negative ideas about their gender group than could women who identify weakly. For example, Major, Quinton, and Schmader (2003; for a review, see Major, McCoy, Kaiser, \& Quinton, 2003) found that highly identified women were particularly prone to detect discrimination when it was not certain but relatively likely. Also, according to Benokraitis (1997; see also Crocker \& Major, 1989), subtle discrimination is particularly effective simply because it is fundamentally ambiguous (i.e., people have a hard time deciding whether this is sexism or politeness). Thus, although benevolence may appear less ambiguous for strongly than for weakly identified women, they may experience uncertainty and mental intrusions because of the incompetence implicitly suggested to characterize women. In contrast, when confronted with relatively clear instances of hostile sexism, strongly identified women might be better able than those who are weakly identified to prevent intrusive thoughts from interfering with performance by blaming the obviously sexist attitude.

\section{Overview}

In a series of four experiments, we proposed to test the specific consequences of hostile and benevolent sexism on women's performance within a feminine domain. Two alternative processes were considered. On one hand, hostile sexism should be more easily identified as sexism compared with benevolent sexism. Benevolent sexism might nevertheless be experienced as quite unpleasant. Therefore, we believed that neither type of sexism would lead to differentials in women's motivation to perform. However, we proposed that benevolent sexism-by implicitly suggesting women's lack of ability and because such thoughts could not easily be externally attributed-would trigger mental intrusions and self-doubt that would interfere with working memory capacity and impair performance. In contrast, because hostile sexism would be easily identified as sexism, related statements would be more easily blamed on the person expressing them and fewer mental intrusions should be experienced. We thus propose that a cognitive rather than a motivational process would be responsible for the deterioration of women's performance under benevolent sexism.

In all four experiments, we used a job selection context in which the position required typically feminine characteristics. We experimentally manipulated the type of sexism expressed (hostile vs. benevolent) and measured its impact on the performance of women in tasks involving working memory. Experiment 1 tested the hypothesis that benevolent sexism, being subtle, would indeed not be perceived as sexism by female participants, whereas hostile sexism would be. Although performance was hypothesized to be affected by the type of sexism, we expected equal motivation to perform in both conditions. The inclusion of a control condition with no expressed sexism also allowed us to examine whether hostile sexism increased performance, whether benevolent sexism decreased performance, or whether both impacted performance. 
Experiment 2 tested the hypothesis that, although not identified as such, benevolent sexism would be perceived as equally unpleasant as hostile sexism but would nevertheless lead to worse performance. In Experiment 3, we focused on two different manipulations of benevolent sexism in order to ascertain that impaired performance was due to sexism per se rather than to some other variables. Finally, Experiment 4 examined the role of thought intrusions elicited by benevolent sexism in causing the deterioration of performance. This fourth study also investigated the potentially protective role of gender identification on women's reactions to sexism.

\section{Experiment 1}

Experiment 1 was presented as a simulation of a job selection interview. The type of sexism was manipulated through the instructions allegedly given by a recruiter being hostile, benevolent, or nonsexist in content. Participants were asked to imagine that they were job applicants and to complete tasks that would inform hiring decisions. In addition to the effect of benevolent and hostile sexism on performance, we investigated the extent to which both kinds of sexism were perceived as being sexism and examined the impact on the motivation to perform. Following Barreto and Ellemers (2005), we predicted that participants confronted with benevolent sexism would fail to recognize it as a form of prejudice, whereas hostile sexism would be easily detected as sexism. We hypothesized, however, that both hostile and benevolent sexism would trigger a high motivation to perform. Motivation to perform could be seen as a kind of angry revenge (see e.g. Kaiser \& Miller, 2001). Indeed, benevolent sexism, although not identified as sexism, might be perceived by women also as unpleasant. However, because unpleasantness could not be externally attributed, benevolent sexism would trigger doubts and diminish performance.

\section{Method}

\section{Participants}

Thirty-eight relatively uneducated French-speaking women (25 to 42 years old; 6 to 9 years of education) were recruited from a government school for adults to participate in a study of job selection. This school helps poorly educated, unemployed adult women to acquire better knowledge and skills in order to increase their employment chances. We reasoned that unemployed adult women were probably confronted by sexism in their everyday life, and therefore sexism manipulations would be most relevant to them. Participants were randomly assigned to expressions of one of three types of sexism (hostile vs. benevolent vs. none). The job for which they supposedly applied was described as requiring typically feminine qualities. That is, the job description matched jobs for which these women would usually apply.

\section{Materials and Procedure}

Cover story. The experiment was presented as part of training for job interviews. All instructions were presented in written format. Participants were told that a chemical factory was offering new jobs and was currently employing men. The recruiting procedure included performing a test that was said to be well-known and frequently used for job recruitment. Testing was performed in group sessions as is often the case in real-world settings. After performing the task and answering some additional questions, participants were fully debriefed and thanked for their participation. Special care was directed to communicating the point of the study because some participants may have felt badly, especially in cases of low performance.

Manipulation of sexism. Instructions said to come from the recruiter expressed hostile, benevolent, or nonsexist attitudes. Hostile and benevolent sexist comments were based on matching items of the ASI (Glick \& Fiske, 1996; see Dardenne, Delacollette, Grégoire, \& Lecocq, 2006, for a French validation). That is, our manipulations included manifestations of hostile or benevolent sexism such as the ones tapped by the scale validating these concepts. In other words, sexist cues in our experimental design corresponded to explicit expressions of the corresponding attitudes measured by the ASI. Specifically, hostile sexism was reflected through the ideas that women belong to the "weaker sex," that they get offended too easily, and that they often exaggerate their situation at work to get more favors. Items such as these suggest men's superiority over women and the idea of women being difficult in order to gain more relative power. All these could be perceived by women as unfair considerations. Alternatively, benevolent sexism was reflected through the ideas that women are nice but that they need to be helped by men, implicitly suggesting then that they lack ability. Such a component of benevolent sexism refers to paternalism.

Specifically, in both sexism conditions, it was explained that a new law on quotas obliged the industry to follow certain employment rules. In the hostile sexism condition, the recruiter's instructions were as follows: "Industry is now restricted to employ a given percentage of people of the weaker sex. I hope women here won't be offended, they sometimes get so easily upset! You'll work with men only, but don't believe what those feminists are saying on TV, they probably exaggerate women's situation in industry simply to get more favors!" In the benevolent sexism condition, the recruiter's instructions were as follows: "Industry is now restricted to choose women instead of men in case of equal performance. You'll work with men only, but don't worry, they will cooperate and help you to get used to the job. They know that the new employee could be a woman, and they agreed to give you time and help." Sexist attitudes might thus be attributed to both the recruiter and the potential colleagues in both sexist conditions. In the no-sexism condition, the recruiter's instructions contained nothing more than the job description. As part of the cover story, the fact that the job included working with men was salient in all conditions.

Job description. The job was never described in great detail. Participants were informed that the job required communication and social skills as well as work-team orientation. The abilities mentioned as required for the job were "sensitive to clients" needs," "cooperative orientation," "good social abilities," and "attentive to clients." That is, the job was presented as requiring quite typically feminine characteristics, such that participants would consider it as relevant to themselves and matching their personal skills.

Test said to be the basis for hiring decisions. The test consisted of nine problem-solving items. Participants were presented with a $4 \times 4$ square representing an ocean with each intersection corresponding to a specific location identified by a letter (going 
from $\mathrm{F}$ to $\mathrm{U})$. Each item identified the location of a ship by a letter, and participants' task was to estimate the shortest way for the ship to travel from that location to another assigned location. Each intersection between two letters was said to equal a distance of 2 $\mathrm{km}$. Importantly, some rules also had to be taken into account with respect to the force and direction of both wind and current as indicated by either one or two arrows (going from left to right, from top to down or the other way around). One arrow indicating the same direction as the ship's direction meant that the distance was $1 \mathrm{~km}$ less than otherwise; one arrow indicating a direction opposite to the ship's direction meant that the distance was $1 \mathrm{~km}$ more than otherwise. Two arrows indicated a force equivalent to 2 $\mathrm{km}$. Arrows directed on the ship's sides were not to be taken into account. Problem-solving items were presented as follows: "The ship is on location I and destination is $\mathrm{P}$, wind is $\uparrow \uparrow$ and current is $\downarrow$. How far is the distance from I to P?" The correct answer for that item was $8 \mathrm{~km}$. Because of the substantial information that had to be taken into account, substantial working memory capacity was required to perform the task. The test comprised 9 items specifying the starting and ending locations of the ship as well as the direction and force of both wind and current. The solution to each item could be correct, incorrect, or not provided. Correct answers ranged from 0 to 9 . Ten minutes were provided to complete the test.

Dependent variables. The participants' performance was evaluated by the number of absolute correct answers provided on the test. The number of items attempted was also analyzed as a separate dependent variable. Perceived sexism was measured right after the manipulation ("Do you find that the introductory text was sexist?"). Motivation to perform was added as a potentially contributing variable (eight items; e.g., "I wanted to prove something during the test," "I gave my best during the test," and "I would like to know my score on the test"; $\alpha=.65$ ).

\section{Results}

All dependent variables were analyzed using a one-way, threelevel analysis of variance (ANOVA) with sexism (hostile vs. benevolent vs. none) as a between-subjects variable.

\section{Perceived Sexism}

As expected, the sexism expressed by the recruiter had a significant effect on perceived sexism, $F(2,37)=10.49, p<.001$, $\eta^{2}=.37$ (see Table 1). Participants confronted by a recruiter manifesting hostile sexism perceived more sexism $(M=5.00)$ than did those who faced benevolent sexism $(M=1.64), t(25)=4.56$, $p<.001, \eta^{2}=.45$, or no sexism $(M=2.64), t(22)=2.75, p<$ $.02, \eta^{2}=.26$. The latter two conditions did not differ significantly from one another, $t(23)=1.36, p>.18$.

\section{Test Said to Be the Basis for Hiring Decisions}

Performance. The sexism expressed by the recruiter had a significant effect on performance, $F(2,37)=12.37, p<.001$, $\eta^{2}=.41$ (see Table 1 ). When confronted by benevolent sexism, participants performed worse $(M=1.57)$ than when the recruiter manifested hostile sexism $(M=6.31), t(25)=4.66, p<.001$, $\eta^{2}=.47$, or no sexism $(M=4.64), t(23)=3.98, p<.001, \eta^{2}=$
Table 1

Perceived Sexism, Performance, Number of Items Attempted, and Motivation to Perform in Experiment 1

\begin{tabular}{lccc}
\hline & \multicolumn{3}{c}{ Type of sexism } \\
\cline { 2 - 4 } \multicolumn{1}{c}{ Variable } & Hostile & Benevolent & None \\
\hline Perception of sexism & $5.00_{\mathrm{a}}$ & $1.64_{\mathrm{b}}$ & $2.64_{\mathrm{b}}$ \\
Performance & $6.31_{\mathrm{a}}$ & $1.57_{\mathrm{b}}$ & $4.64_{\mathrm{a}}$ \\
No. of items attempted & $8.31_{\mathrm{a}}$ & $7.71_{\mathrm{a}}$ & $7.91_{\mathrm{a}}$ \\
Motivation to perform & $4.89_{\mathrm{a}}$ & $4.24_{\mathrm{a}}$ & $4.16_{\mathrm{a}}$ \\
\hline
\end{tabular}

Note. Means with different subscripts differ significantly at $p<.05$.

.41. The last two conditions did not differ significantly from one another, $t(22)=1.41, p>.17$.

Number of items attempted. There were no significant differences in the number of problems attempted by participants between the benevolent $(M=7.71)$, hostile $(M=8.31)$, or no-sexism conditions $(M=7.91), F(2,37)<1, n s$. Overall, participants attempted to solve a large proportion of items (89\% of items).

Motivation to perform. Motivation to perform was not affected by the type of sexism expressed through the recruiter's instructions, $F(2,37)=1.60, p>.21$. Globally, participants manifested quite a positive motivation to perform $(M=4.44, S D=1.14)$.

\section{Mediation Analysis}

To examine whether the effect of sexism on performance could be mediated by women's perceiving sexism, we performed four regression analyses (Baron \& Kenny, 1986). First, performance was regressed on the type of sexism (hostile sexism $=-1$; benevolent sexism $=1$ ) as a unique predictor. Replicating the above ANOVA, analyses revealed significant sexism effects, $\beta=$ $-.68, t(25)=-4.66, p<.001$. Second, perceived sexism was also regressed on the type of sexism. Again, the sexism of the recruiter had a significant effect on perceived sexism, $\beta=-.67$, $t(25)=-4.56, p<.001$. Third, the analysis with perceived sexism as a predictor of performance was significant, $\beta=.66$, $t(25)=4.35, p<.001$. Finally, performance was regressed on manipulated sexism and perceived sexism simultaneously. As can be seen in Figure 1, perceived sexism no longer significantly predicted performance, $\beta=.36, t(25)=1.91, p=.07$; the effect was now much smaller and marginal. Manipulated sexism, on the other hand, was still a significant predictor of performance, $\beta=$ $-.44, t(25)=-2.33, p<.05$. A Sobel test also indicated only a marginally significant reduction in the predictive power of sexism on performance $(z=-1.76, p<.08)$. Thus, if anything, perceived sexism only partially mediated the effect of the sexism manipulation on performance.

\section{Discussion}

Results of this first experiment demonstrated that the type of sexism a recruiter expressed toward female job applicants did matter and impacted their actual performance. As predicted, it was under conditions that would seem the most benign-when benevolent sexism was expressed - that outcomes were most detrimental to women. Consistent with the fact that benevolent sexism is usually much 


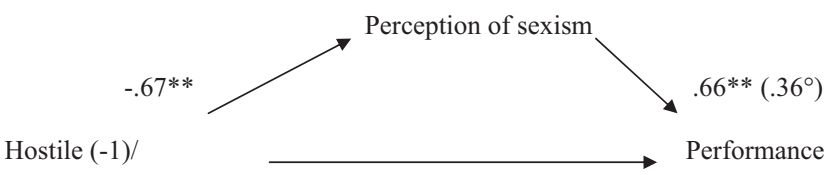

Benevolent (1) sexism

$$
-.68 * *(-.44 *)
$$

Figure 1. Perceived sexism as a mediator of performance in response to sexism (Experiment 1). Coefficients in parentheses represent parameter estimates for a regression model containing both predictors. ${ }^{\circ} p=.07$. ${ }^{*} p<.05 .{ }^{* *} p<.001$.

subtler and more accepted than hostile sexism (e.g., Barreto \& Ellemers, 2005), results indicated that our benevolent sexism condition led women to qualify the context as no more sexist than when no sexism was present in the recruiter's instructions. Still, benevolent sexism significantly diminished the performance of women compared with a context in which no sexism was expressed. In contrast, hostile sexism was clearly identified as being a form of prejudice but did not impair performance. Rather, expressing sexism through its hostile form led women's performance to be good enough and similar to that in the control condition.

One possible explanation for the difference in performance between benevolent and hostile sexism conditions could be that hostile sexism-because it was identified as sexism and perceived as unfair-increased women's motivation to perform, which in turn preserved their performance. Results, however, did not support such a revenge- or anger-based reaction. In fact, the type of sexism expressed by the recruiter did not affect the motivation to perform. In addition, perceiving hostile sexism as sexism did not fully mediate the positive impact it had on performance, compared with its benevolent counterpart. Although Experiment 1 ruled out the possibility that hostility led to a revenge reaction that would increase motivation to perform, it remained nevertheless plausible that hostility led to perceiving the job itself as more motivating to women than when they were confronted with benevolence. Experiment 2 addressed the possibility that a revenge reaction to hostility would be directed to the way the job itself was evaluated.

Although not identifying benevolent sexism as being sexism was perfectly consistent with the literature, the results might seem surprising. If not perceived as such, how could benevolent sexism affect performance? Not identifying benevolent sexism as a form of prejudice does not mean that women considered benevolent sexist manifestations to be similar to nonsexist contexts. Indeed, it would be reasonable to think that, because benevolent sexist comments could indicate well-intentioned attitudes as well as unpleasant sexism, women might have hesitated to qualify such attitudes as being sexist. Nevertheless, if, as we proposed, benevolent sexism implicitly suggests that women lacked abilities, women should have considered it to be as awkward as hostile sexism. Experiment 2 examined the perceived pleasantness of the context as a variable that covaries with sexism and indicates women's ability to distinguish expressions of benevolent sexism from situations in which no sexism is expressed.

Finally, we proposed to generalize the findings of Experiment 1 on other criteria. Experiment 1 used a simulated job selection that was presented in a written format to a population of poorly educated, unemployed women. In Experiment 2, we focused on a population of university female students, thus a more educated sample than participants in Experiment 1, and again manipulated the type of sexism. In order to further increase the ecological validity of our design, the experimenter role-played a recruiter behaving in a hostile, benevolent, or nonsexist manner.

\section{Experiment 2}

Method

\section{Participants}

Forty-five undergraduate females from the University of Liège volunteered to participate in a study on job selection (age ranged from 18 to 23 years old). They were randomly assigned to three conditions of sexism (hostile vs. benevolent vs. none). They participated in group sessions of 7 to 12 participants. In order to ensure gender salience, we allowed males to participate in the study so that every group session was gender mixed. Data for the (very few) male participants were not analyzed.

\section{Materials and Procedure}

Materials and procedure were essentially identical to those in Experiment 1, except that all instructions and manipulations were role-played. In order to evaluate women's capacity to distinguish benevolent sexism from no sexism on a variable other than perception of sexism per se, we asked participants how pleasant they perceived the context. We also measured participants' motivation to get the job with a special focus on evaluations of the job itself. Participants were then fully debriefed with special attention to the reasons leading to their possibly having performed badly and were thanked for their participation.

Cover story. The experiment was presented as being part of the male experimenter's practicum on work and organizational psychology during which he had to train as a recruiting officer. Therefore, participants were asked to imagine that they were job applicants. Apart from that point, the cover story, job description, and test said to be the basis for hiring decisions were identical to those in Experiment 1. After the main test, participants were asked to answer a series of questions aimed at helping the experimenter improve his skills as a recruiting officer.

Manipulation of sexism. The male recruiter expressed either hostile or benevolent sexist comments (explicit manifestations of attitudes), or he expressed no sexism. The comments were identical to the written instructions presented in Experiment 1.

Dependent variables. Performance was evaluated by the number of correct answers provided on the test. The number of items attempted was also analyzed as a separate dependent variable. In addition, we measured how pleasant the context was perceived to be. This included evaluations of both the recruiter and the interview (six items: "The interviewer was nice," "The interviewer was competent," "The interviewer was sympathetic," "The interview was nice," "The interview was too long," and "The interview was frustrating," with the last two items being reversed-coded; $\alpha=$ .78), and the participants' motivation to get the job (two items: "I was really motivated to get the job" and "I've totally played the game to get the job," $r(43)=.61, p<.001)$. All answers were on a 9-point Likert like scale (from $1=$ not at all to $9=$ extremely). 


\section{Results}

All dependent variables were analyzed in a one-way ANOVA with a three-level between-subjects variable, sexism (hostile vs. benevolent vs. none).

\section{Motivation to Get the Job and Perceived Pleasantness of the Context}

As can be seen in Table 2, motivation to get the job was not affected by the recruiter's expressed sexism, $F(1,42)<1$. Analyses of perceived pleasantness of the context revealed an effect of the sexism manipulation, $F(1,42)=15.53, p<.001, \eta^{2}=.43$. More specifically, both hostile $(M=6.53)$ and benevolent $(M=$ 6.06) sexism conditions were moderately positive and did not differ from one another, $t(33)=1.19, p>.24$. Importantly, participants perceived both sexist contexts as significantly less positive than the nonsexist condition $(M=8.30), t \mathrm{~s}(24$ and 27$)>$ 4.55, $p$ s $<.001$, both $\eta^{2}>.46$.

\section{Test Said to Be the Basis for Hiring Decisions}

Performance. As can be seen from Table 2, the type of sexism expressed by the recruiter had a significant impact on performance, $F(2,42)=6.03, p<.005, \eta^{2}=.22$. Replicating Experiment 1 , participants confronted with a recruiter expressing benevolent sexist attitudes performed worse than did participants confronted by either a hostile sexist recruiter, $t(33)=2.12, p<.05, \eta^{2}=.12$, or a nonsexist recruiter, $t(27)=2.97, p<.01, \eta^{2}=.25$. The last two conditions were not significantly different from one another, $t(24)=1.81, p>.08$.

Number of items attempted. The sexism expressed by the recruiter had no significant impact on the number of items attempted, $F(2,42)<1$. Globally, almost all participants attempted to solve each of the nine items within the time allotted for the test (see Table 2).

\section{Discussion}

Results of Experiment 2 were straightforward. We perfectly replicated Experiment 1's results on performance with a different sample of participants and with a role-play instead of written instructions. Moreover, hostility did not lead participants to be more motivated to get the job than benevolent sexism or neutral conditions. Confirming Experiment 1, performing well when confronted with hostile sexism was not the result of a revenge reaction. Furthermore, both hostile and benevolent sexism led partic-

Table 2

Motivation to Get the Job, Pleasantness of the Context, Performance, and Number of Items Attempted in Experiment 2

\begin{tabular}{lccc}
\hline & \multicolumn{3}{c}{ Type of sexism } \\
\cline { 2 - 4 } \multicolumn{1}{c}{ Variable } & Hostile & Benevolent & None \\
\hline Motivation to get the job & $6.16_{\mathrm{a}}$ & $5.94_{\mathrm{a}}$ & $6.85_{\mathrm{a}}$ \\
Pleasantness of the context & $6.53_{\mathrm{a}}$ & $6.06_{\mathrm{a}}$ & $8.30_{\mathrm{b}}$ \\
Performance & $7.50_{\mathrm{a}}$ & $5.63_{\mathrm{b}}$ & $8.60_{\mathrm{a}}$ \\
No. of items attempted & $8.94_{\mathrm{a}}$ & $8.95_{\mathrm{a}}$ & $9.00_{\mathrm{a}}$ \\
\hline
\end{tabular}

Note. Means with different subscripts differ significantly at $p<.01$. ipants to view the context as more negative than in the absence of sexism. Importantly, although Experiment 1 suggested that women did not explicitly identify benevolent sexism as being sexism, they nevertheless considered it equally as unpleasant as hostile sexism. That is, even if women did not identify benevolent sexism as such, they were not insensitive to its expression.

Confronting benevolent sexism resulted in women performing worse than when confronted with hostile sexism. This result could definitely not be attributed to hostile sexism increasing women's motivation to perform as a revenge- or anger-related mindset. Indeed, although performance was better when hostile rather than benevolent sexist attitudes were faced, motivation to get the job was equivalent in all three conditions. Therefore, we proposed that two key elements would be responsible for women's decreased performance: first, the implicit suggestion that women lack ability communicated through benevolent sexism, and second, the difficulty of making external attributions for these statements (i.e., blaming the recruiter).

Still, our specific manipulation of sexism was open to an alternative interpretation. In Experiments 1 and 2, we manipulated benevolent sexism through instructions that started with the idea that the firm was required to hire women ("choose women instead of men in the case of equal performance") and then further warned them that they would receive help from men. Following the work of Heilman and others, this statement of preferential selection policies and offer of unsolicited help could by itself have had a negative effect on women's performance (e.g., Heilman \& Alcott, 2001; Nadler \& Fisher, 1986; Schneider, Major, Luhtanen, \& Crocker, 1996; Turner \& Pratkanis, 1994). However, we doubt that the mention of preferential selection policies could be responsible for the decrease in performance. Indeed, both hostile and benevolent sexism conditions included such references, though only benevolent sexism impaired performance. Nonetheless, expressing benevolent sexist attitudes such as providing help in conjunction with the salience of preferential selection policies could have raised some levels of suspicion regarding the sincerity of the apparently positive attitude displayed. Yet another explanation of our results would be that unsolicited help rather than benevolent sexism per se affected the performance of women. As a matter of fact, our manipulation of benevolent sexism focused on its paternalistic component and suggested that men would help women who would be hired. In order to rule out these alternative explanations, we again tested the hypothesis of a detrimental effect of benevolent sexism on performance in Experiment 3, but using a manipulation of benevolent sexism that did not contain any offer of unsolicited help and instructions that did not mention any preferential selection policies.

Another specific aspect of our material could also be seen as problematic. Indeed, even though we presented the job as requiring feminine qualities, the task said to be the basis for the hiring decision might have been seen as rather masculine. Even if we took great care not to imply any stereotypic expectations, our task nevertheless required visual-spatial abilities with which women might have felt uncomfortable. Selection procedures in real-world settings often make use of psychometric tests, whatever the job that is being applied for, assessing mental rotation, visual-spatial abilities, logical deduction, or mathematic abilities. However, participants might have perceived this task as having little face value in tapping the qualities required for the job or might have per- 
ceived the task in itself a threat. Because the task was the same in all three conditions but led to low performance only when benevolent sexism was expressed, we doubt that this would be the case. Indeed, why would women doubt their abilities to perform such a task only when benevolent sexism was expressed, except if benevolent sexism was suggesting their inferiority? Nevertheless, one could argue that the ideas suggested by benevolent sexism were relevant only when women were confronted with a task that was ambiguous enough to be perceived as either stereotyperelevant or -irrelevant. In order to rule out that hypothesis and examine whether benevolent sexism per se had an impact on performance, we used a performance task in Experiment 3 that could not be seen as masculine in any of its characteristics and would thus provide better face validity in regard to the qualities required for the job.

\section{Experiment 3}

Experiment 3 was presented as a simulation of a job selection interview. No mention of preferential selection was made in the instructions, and all of them were presented in a written format. The type of sexism was manipulated through instructions manifesting benevolent sexism including either the paternalistic or the complementary gender differentiation component. Paternalism consisted of providing unsolicited help. Complementary gender differentiation consisted of magnifying and emphasizing differences between men and women in a way that favored women without any mention of helping behavior. An additional group received instructions that were not sexist in content. Participants were asked to imagine that they were job applicants and they had to complete a task on the basis of which hiring decisions would be made. For the sake of generalization and to rule out potential alternative explanations in terms of the nature of the task, we included a performance task that could not be seen as masculine or stereotype-relevant in any of its characteristics.

\section{Method}

\section{Participants}

Thirty women recruited on the campus of the University of Liège volunteered to participate in a study of job selection (age ranged from 18 to 22 years old). They were randomly assigned to written instructions conveyed by a recruiter who expressed one of three types of sexism (benevolent sexism with help vs. benevolent sexism without help vs. no sexism). The firm to which they supposedly applied was described as requiring typical feminine qualities.

\section{Materials and Procedure}

Cover story. All instructions were presented in written format. Participants were asked to imagine that they had been searching for a job for several months and had applied for one that they thought would be interesting. They had just received an invitation to go to the interview. The firm proposing the job was known for working with associates who were attentive to clients and sensitive to their needs, provided collaboration, and manifested good social skills (feminine qualities). Participants were told that the firm was a chemical factory that offered new jobs and currently employed men who would be the hired candidates' colleagues. The recruiting procedure was said to include performing a test that is well-known and frequently used for job recruitment. After performing the task, participants were fully debriefed with a special focus on the reasons for possibly having performed badly and then thanked for their participation.

Manipulation of sexism. The written instructions conveyed attitudes expressing benevolent sexism with help (paternalist component), benevolent sexism without help (complementary gender differentiation component), or no sexism. Benevolent sexist comments were based on matching items of either the paternalistic or complementary gender differentiation subcomponents of the ASI (Glick and Fiske, 1996; see Dardenne et al., 2006, for a French validation). In the benevolent sexism with help condition, instructions were as follows: "You have to know that women who may be hired will work with men only. This should not be a problem because all of them agreed to cooperate and help new female colleagues to get used to the job. Moreover, they are fully aware of the importance of helping newly hired women, and all of them agreed to take on the time to help you to adapt the best." In the benevolent sexism without help condition, instructions were as follows: "You have to know that women who may be hired will work with men only. This should not be a problem because they are fully aware of the importance of hiring women in their firm. Indeed, all of them think that the presence of women, who are more cultured and sophisticated than men, will allow the firm to benefit from their moral sense and refined taste, whereas these aspects are often lacking where only men work." Sexist attitudes might thus be attributed to both the recruiter and the potential colleagues in both sexist conditions. In the no-sexism condition, instructions contained nothing more than the description of the firm and cover story, including salience of working with men. In neither case did the recruiter mention any law about quotas or preferential selection in the hiring of women.

Test said to be the basis for hiring decisions. A modified version of the Daneman and Carpenter (1980) Reading Span Test (RST) was used. This test had been developed to measure working memory. The test is known to be a good predictor of reading comprehension and verbal reasoning ability (e.g., Daneman \& Carpenter, 1980; Daneman \& Merikle, 1996). The use of the RST as a measure of central executive functioning was based on the idea that test performance reflects the total amount of attentional resources that can be allocated to information storage and manipulation (Just \& Carpenter, 1992). Importantly, characteristics of that test could not be perceived as being masculine in any way. On each trial of the test, participants were asked to read a set of sentences and to decide whether each sentence was grammatically correct, while simultaneously maintaining the last word of each sentence in their memory (one target word for each sentence). Set sizes ranged from two to six sentences, after which target words had to be recalled. Ten minutes were provided to complete the test. The test was long enough (74 items) to ensure that it would not likely be completed within that period of time.

Dependent variables. Performance was evaluated by the total number of words correctly recalled across all trials. Because cognitive resources devoted to both memory and grammatical decisions might be somehow interdependent, memory performance would also be evaluated with performance on the secondary task being included as a covariate. 


\section{Results}

The participants' performance on the total number of words correctly recalled was analyzed by way of a one-way ANOVA with a three-level between-subjects variable, sexism (benevolent sexism with help vs. benevolent sexism without help vs. no sexism). As can be seen in Table 3, the sexism expressed by the recruiter had a significant effect on recall, $F(2,34)=7.30, p<$ $.002, \eta^{2}=.31$. Least significant difference contrasts confirmed that when confronting benevolent sexism with help $(p<.009)$ or benevolent sexism without help $(p<.001)$, the participants performed worse than when the recruiter manifested no sexism. The two benevolent sexism conditions did not differ from one another, $p>.36$.

When the performance on the secondary task was included as a covariate, the type of sexism expressed by the recruiter still had a significant effect on recall, $F(2,31)=5.47, p<.009, \eta^{2}=.26$. Contrasts confirmed that when confronting benevolent sexism with help or benevolent sexism without help, the participants performed worse than when the recruiter demonstrated no sexism, $p$ s $<.02$. The two benevolent sexism conditions did not differ from one another, $p>.12$.

\section{Discussion}

The main results of Experiments 1 and 2 were replicated with a manipulation of benevolent sexism that did not contain any references to unsolicited help or any mention of a preferential selection of women over men. These results strongly demonstrated that benevolent sexism by itself was a sufficient condition for undermining women's performance. Experiments 1, 2, and 3 demonstrated this effect on two different tasks, both involving working memory capacity. Importantly, although the task used in Experiments 1 and 2 could have been seen as discrepant with the job or perceived as stereotype-relevant, these criticisms could not hold with the RST of Experiment 3.

In addition, the RST used in Experiment 3 helped to further illuminate the effects benevolent sexism had on performance. RST was originally developed to assess "people's ability to perform active processing of a stimulus while simultaneously buffering other information in working memory" (Whitney, Arnett, Driver, \& Budd, 2001, p. 2). Scores on the RST also predicted performance on tasks that require inhibition of irrelevant thoughts and information (Rosen \& Engle, 1998). In our view, impaired scores on the RST after confronting benevolent sexism suggested that women suffered many interfering and irrelevant thoughts.

Table 3

Performance as a Function of Sexism in Experiment 3

\begin{tabular}{lccc}
\hline & \multicolumn{3}{c}{ Type of sexism } \\
\cline { 2 - 4 } Performance & $\begin{array}{c}\text { Benevolent } \\
\text { with help }\end{array}$ & $\begin{array}{c}\text { Benevolent } \\
\text { without help }\end{array}$ & None \\
\hline Recall & $27.40_{\mathrm{a}}$ & $22.30_{\mathrm{a}}$ & $38.60_{\mathrm{b}}$ \\
Grammar/semantic & $27.00_{\mathrm{a}}$ & $33.70_{\mathrm{a}}$ & $41.50_{\mathrm{b}}$ \\
\hline
\end{tabular}

Note. Means with different subscripts differ significantly at $p<.01$.
Experiments 1, 2, and 3 repeatedly demonstrated that benevolent sexism had a negative effect on performance compared with both hostile and nonsexist conditions. Moreover, we provided evidence that the effect of benevolence was not caused by the motivation to perform on the test, the motivation to get the job, or the perception of sexism. Importantly, Experiment 3 also demonstrated that women's impaired performance was not due to the fact that benevolent sexism included unsolicited help. Indeed, even when benevolent sexism was manipulated through its complementary gender differentiation component, that is, even when absolutely no helping attitudes were used, benevolence still undermined women's performance. Finally, the same effect was found even when no preferential selection policies were mentioned. It was thus unlikely that women were suspicious regarding the sincerity of the apparently positive attitude displayed because the context did not provide any cue allowing them to do so.

Interestingly, when benevolent sexism was expressed to women, they found it difficult to identify it as sexism while simultaneously considering the situation unpleasant. This might indicate that they faced much more ambiguity and doubt about how to identify the situation, compared with when hostile sexism was expressed. Indeed, when identifying (hostile) sexism in the recruiter's discourse, participants knew what to think about his opinions, so his remarks could more easily be discounted or externally attributed (Crocker \& Major, 1989). Certainly, when confronted with benevolent attitudes or with males' willingness to help them, women may have had trouble deciding whether they should attribute such interactions to sexism. Importantly, doubts about how to appraise benevolent sexist remarks would be raised only if such discourse implicitly suggested that women somehow lack ability, together with the praising aspects (helping or magnifying women) it involved. Benevolent sexism promotes the idea that women lack competence, and internal rather than external attributions for such ideas are more likely. Such a subtle form of sexism might then lead women to doubt their abilities to perform well, to experience a decrease in their self-esteem and self-confidence, as well as to be preoccupied during the task. Interfering thoughts such as these, through taxing cognitive resources required for working memory tasks, could then definitely have impaired performance. In contrast, hostile sexism likely generated much less intrusive thought because hostility was explicitly manifested. The unpleasantness of the situation can thus more easily be attributed to the recruiter's attitude (external attribution), leaving sufficient cognitive resources to devote to the task at hand. Experiment 4 examined that hypothesis.

\section{Experiment 4}

Experiment 4 was designed to examine the role of interfering thoughts in explaining benevolent sexism's deleterious effect on women's performance. On the specific tests we used, high performance required working memory. Using the same procedure as in Experiments 1 and 2, we included in this experiment measures of preoccupation with the task, self-doubt, and performance self-esteem (Heatherton \& Polivy, 1991). First, we hypothesized that benevolent sexism, compared with hostile sexism, would lead to the deterioration of women's performance. Second, we proposed that benevolent sexism would lead to greater mental intrusions and that this would be revealed through greater preoccupation with the task, greater doubts, 
and impaired performance self-esteem. Third, we hypothesized that the level of mental intrusions elicited by benevolent sexism would mediate its impact on women's performance. Additionally, because sexism tackles women as a group, gender identification may well moderate the effects sexism had on performance and mental intrusions. Experiment 4 thus included measures of gender identification to see whether it would moderate the impact of sexism on women's performance and mental intrusions.

\section{Method}

\section{Participants}

Forty-four low-educated women (aged 25 to 42 years old; 6 to 9 years of education) from the same government school as in Experiment 1 volunteered to participate in a study on job selection. They were randomly assigned to the expression of one of two types of sexism (hostile vs. benevolent) communicated through written instructions. As in Experiments 1-3, the job for which they supposedly applied was described as requiring typically feminine qualities.

\section{Materials and Procedure}

At the beginning of the experimental session, participants completed three items assessing the identification with their gender group on a 9-point scale, with endpoints of 1 (do not agree) and 9 (agree totally): "I have many characteristics in common with other women," "I identify with the group of women," and "Being a woman is a very important reflection of who I am" $(\alpha=.98)$. Next, the cover story, material, and procedure were identical to Experiments 1 and 2. In addition, preoccupation with the task, self-doubts, and performance self-esteem were used as indicators of mental intrusions. After performing the task, participants were fully debriefed, with a special focus on the reasons for possibly performing badly, and thanked for their participation.

Dependent variables. Performance and the number of items attempted were examined, as in Experiments 1 and 2. Mental intrusions, as a potential mediating variable, were also measured. Specifically, seven items assessed the level of preoccupation experienced during the task (e.g., "During the task, I thought that my performance would be poor," "During the task, I felt my heart beating more strongly," "During the task, I wasn't sure about the rules associated with wind and current"; $\alpha=.97$ ). The level of self-doubt experienced after performing the task was measured with a series of 13 items (e.g., "Right now, I feel full of doubt," "Right now, I feel frustrated by my performance," "Right now, I'm worried"; $\alpha=.98)$. Then the participants completed seven items from Heatherton and Polivy's (1991) Performance Self-Esteem subscale (e.g., "Right now, I am having trouble understanding what I'm reading," "Right now, I am frustrated or worried by my performance," "Right now, I am confident in my capacity"; $\alpha=.92$ ). All items ranged from 1 (not at all) to 9 (totally). Responses were coded such that agreement with items reflected greater preoccupation, greater self-doubt, and lower performance selfesteem. ${ }^{1}$

\section{Results}

The data were analyzed using multiple regression, with sexism (contrast-coded -1 if hostile and +1 if benevolent), identification to the ingroup (centered; $M=5.87, S D=2.26$ ), and the interaction between them as predictors (Brauer, 2002; Cohen, 1983; Judd, 2000).

\section{Test Said to Be the Basis for Hiring Decisions}

Performance. Replicating Experiments 1-3, sexism had a significant effect on performance, $\beta=-.64, p<.001$. When confronting benevolent sexism, the participants performed worse $(M=2.35)$ than when facing hostile sexism $(M=4.62)$. Gender identification was also related to the women's performance, $\beta=$ $.35, p<.005$, such that highly identified women performed better than low-identified women. These effects were qualified by a significant interaction between sexism and identification, $\beta=$ $-.28, p<.05$. As can be seen in Figure 2, identification had no effect on performance when women confronted a benevolent sexist attitude, $\beta=.16, p>.45$. When facing hostile sexism, however, women with stronger identification with the gender group performed better, $\beta=.58, p<.01$.

Number of items attempted to be solved. The only significant effect was that hostile sexism led participants to attempt to solve more items than did benevolent sexism, $\beta=-.46, p<.005$. Globally, hostile sexism led participants to give answers to a greater number of items $(M=7.38)$ than did benevolent sexism $(M=5.26)$. Neither the identification $(\beta=.14, p>.30)$ nor the interaction emerged as significant $(\beta=-.16, p>.25)$.

\section{Mental Intrusions}

We examined the relationships among the three measures of mental intrusions (preoccupation, self-doubt, and self-esteem), which revealed very strong correlations, $r \mathrm{~s}(44)>.93, p \mathrm{~s}<.001$. We thus aggregated them into a global measure of mental intrusions. In fact, a factor analysis indicated that all 27 items loaded on a single factor, explaining $87 \%$ of the variance $(\alpha=.97)$. The mental intrusions regression revealed a significant effect of sexism, $\beta=.71, p<.001$. As hypothesized, the participants reported more mental intrusions when they had been confronted by benevolent $(M=6.63)$ rather than hostile sexism $(M=3.06)$. As can be seen in Figure 3, the effect of identification was also significant, $\beta$ $=-.29, p<.05$, showing globally fewer mental intrusions for highly identified women. The interaction was, however, not significant, $\beta=.13, p>.20 .^{2}$

\section{Mediation Analysis}

Our mediation hypothesis concerning the effects of hostile and benevolent sexism on performance and number of items attempted was tested in a regression analysis including both sexism (coded as -1 if hostile and +1 if benevolent) and mental intrusions as

\footnotetext{
${ }^{1}$ The items are available from Benoit Dardenne.

${ }^{2}$ Although the Performance Self-Esteem scale was referring to interfering thoughts such as "I have the feeling that I'm not as smart as the others," it might be considered as conceptually distant from other intrusive thoughts. Therefore, analyses were also conducted on the Mental Intrusions scale without the specific subscale of Performance Self-Esteem and on performance self-esteem separately. Analyses revealed exactly the same for both subscales separately as for the scale when it was composed of the 27 items.
} 


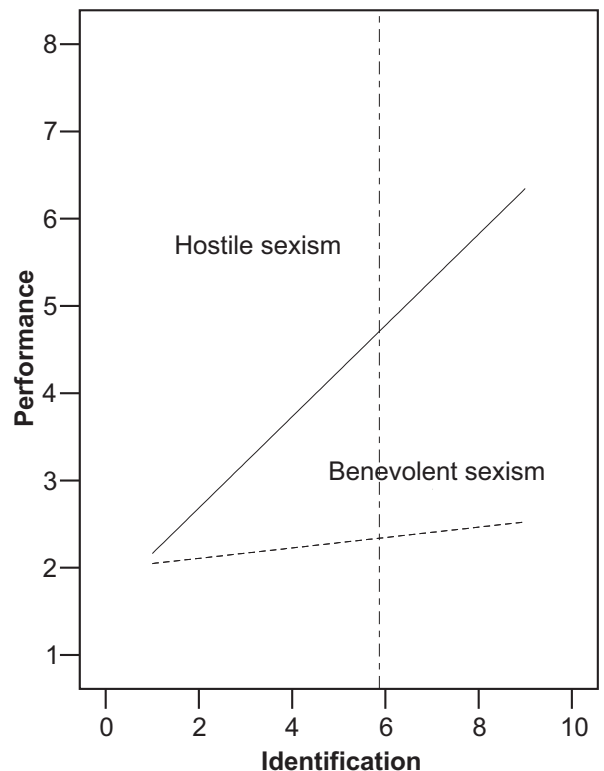

Figure 2. Relationship between performance and level of identification according to the type of sexism (Experiment 4). The vertical bar represents the mean level of identification.

predictors. According to Baron and Kenny (1986), three relationships must be demonstrated in order to test mediation (see Figure $4)$, and we tested them all. First, we showed that our manipulation of sexism predicted mental intrusions $(\beta=.68, p<.001)$, performance $(\beta=-.61, p<.001)$, and number of items attempted $(\beta$ $=-.43, p<.005)$. Second, mental intrusions predicted performance $(\beta=-.87, p<.001)$ as well as number of items attempted $(\beta=-.61, p<.001)$. Third, as can be seen in Figure 4 , the direct

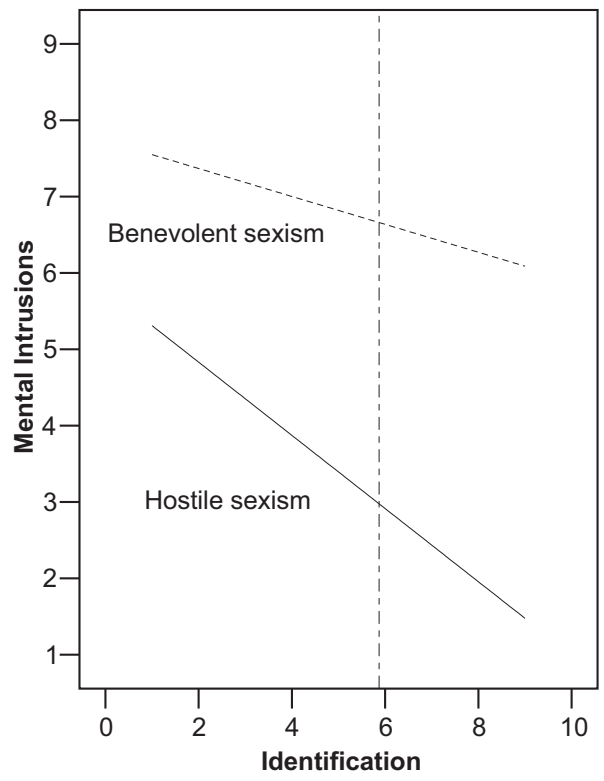

Figure 3. Relationship between mental intrusions and level of identification according to the type of sexism (Experiment 4). The vertical bar represents the mean level of identification.
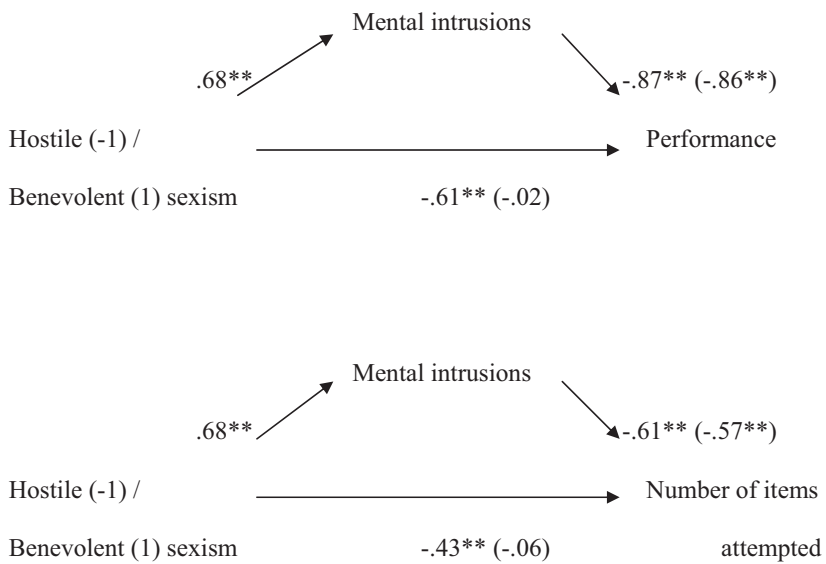

Figure 4. Mental intrusions as a mediator of performance (top) and number of items attempted (bottom) in response to the type of sexism (Experiment 4). Coefficients in parentheses represent parameter estimates for a regression model containing both predictors. ${ }^{* *} p<.005$.

effect of the recruiter's sexism became negligible and even virtually null when the index of mental intrusions was entered into each regression analysis, $\beta=-.02, p>.80$, for performance, and $\beta=$ $-.06, p>.70$, for number of items attempted. Sobel tests further confirmed that the reductions in the direct effect of the recruiter's sexism on performance and number of items attempted were significant $(z=-4.94$ and $-2.95 ; p<.001$ and .005 , respectively). Thus, the impact of our sexism manipulation on performance and number of items attempted seemed fully mediated through the influence it had on mental intrusions. More mental intrusions (doubts, preoccupation with the task, and lowered selfesteem) lowered performance and led participants to attempt to solve fewer items. That is, through the preoccupations it activated, benevolent sexism exerted its deleterious impact on women's performance.

To rule out other explanations for these relationships, we also conducted the reverse mediation analyses with performance or number of items attempted as mediators and mental intrusions as the dependent variable. In each regression, the sexism manipulation remained a significant predictor of mental intrusions when we controlled for performance or number of items attempted (both $\beta \mathrm{s}>.24), t \mathrm{~s}(43)>2.82, \mathrm{ps}<.01 .^{3}$

\section{Discussion}

Experiment 4 provided additional support for the hypothesis that benevolent sexism had a negative effect on performance compared with a hostile form of sexism. Most importantly, Experiment 4 examined the mechanism through which benevolent sexism affected performance. Indeed, benevolent sexism led women to experience many mental intrusions, such as preoccupation with the task, self-doubt, and decreased self-esteem. Such mental intrusions

\footnotetext{
${ }^{3}$ Similar to analyses on mental intrusions, we conducted the mediation analysis with the Mental Intrusions scale without the specific subscale of Performance Self-Esteem and with performance self-esteem separately. The mediation analyses revealed exactly the same for both subscales separately as for the scale when it was composed of the 27 items.
} 
in turn impaired their capacity to concentrate on the task and weakened their working memory, slowing down their performance on the task and damaging global performance (see also, e.g., Beilock \& Carr, 2005; Beilock et al., 2004). In contrast, when hostile sexism was expressed, women faced many fewer mental intrusions and performance was preserved.

Although it was plausible that performing poorly led to preoccupation, self-doubt, and decreased self-esteem, analyses revealed that causality was not in that direction. It was through its impact on mental intrusions that sexism influenced the women's performance. In fact, whatever the status of mental intrusions in the analysis (mediator or outcome variable), sexism always significantly predicted them. On the contrary, performance was no longer predicted by type of sexism when it was considered as an outcome variable and mental intrusions were entered as the mediating variable.

It might be surprising that preoccupation, self-doubt, and performance self-esteem items all loaded on a single factor. In addition, some might argue that mental intrusions such as these were not "pure" and also included anxiety or worries. Indeed, doubts are worries, and doubts include anxiety. Similarly, performance selfesteem precisely taps some anxiety and worries about one's performance, competence, or abilities. Such doubts and preoccupations, being specific to performance or more diffuse, all reflected thoughts that might have interfered with women's working memory capacity and task performance.

Also, we showed that stronger gender group identification led women to be much less prone to interfering thoughts than did lower identification. The interaction between identification and sexism did not emerge as statistically significant. Nevertheless, the pattern of data displayed in Figure 3 was neatly consistent with the proposal that benevolent sexism led to mental intrusions even for highly identified women. That is, when benevolent sexism was expressed, stronger identification did not reduce mental intrusions enough $(\beta=-.28, p>.20)$, and performance decreased. When sexism was expressed in a hostile manner, however, highly identified women seemed better able than low-identified women to reduce mental intrusions $(\beta=-.47, p<.05)$ and to perform well. It thus seemed that benevolent sexism impacted enough for both low-identified and highly identified women to reach the threshold of mental intrusions that was necessary to damage performance, whereas hostile sexism only affected low-identified women sufficiently to undermine a performance.

This is perfectly consistent if we consider that stronger identification helped to diminish negative ideas about the gender group. However, the level of mental intrusions was low enough not to disturb performance only for those women who strongly identified with their gender group in the case where they faced hostile sexism. Identification has often been shown to moderate the impact of blatant discrimination, such that it led to attributing negative feedback to discrimination (e.g., Crocker, Voelkl, Testa, \& Major, 1991; Operario \& Fiske, 2001) or contributing to selfesteem protection (e.g., Major, Quinton, \& Schmader, 2003; McCoy \& Major, 2003). The positive effect of identification, however, might not last long. Correlational studies have shown that chronic exposure to discrimination is indeed related to lower well-being (see, e.g., Branscombe, Schmitt, \& Harvey, 1999; Schmitt, Branscombe, Kobrynowicz, \& Owen, 2002). In the short term, though, our results supported the idea that hostile sexism was less damaging than benevolent sexism, which insidiously created a basis for gender inequality.

\section{General Discussion}

In a series of four experiments, we demonstrated consistent evidence that benevolent, more than hostile, sexism had a deleterious impact on women's performance. Moreover, this was true despite the fact that the context valued feminine qualities. Experiments 1, 2, and 4 used a task that could be seen as rather stereotype-relevant and discrepant from the qualities required for the job offered, but this was not the case in Experiment 3. In all four experiments, it was only when benevolent sexism was expressed that performance decreased. That is, we proposed that women doubted their abilities to perform the task (regardless of whether the task was discrepant with the job offered) only when benevolent sexism was expressed because it suggested women's inferiority, and this idea could not easily be externally attributed. Even though benevolent sexism was more positive in tone, apparently benign, and not identified as prejudice, it was revealed to be a powerful weapon in destroying women's performance within feminine domains.

Although benevolent sexism was not readily identified as sexism (Experiment 1), both hostile and benevolent sexism were experienced as somewhat unpleasant situations (Experiment 2), and benevolent more than hostile sexism generated disturbing mental intrusions (Experiment 4). Experiments 1 and 2 discarded plausible alternative interpretations of our results in terms of motivation to perform, and Experiment 3 ruled out the idea of a simple impact of preferential selection or offer of unsolicited help on the performance of women. In fact, benevolence expressed through complementary gender differentiation alone (i.e., no mention of unsolicited and unwanted help and of preferential selection) was sufficient to decrease the performance of women. Sexism was role-played in Experiment 2 but was conveyed through written instructions in Experiments 1, 3, and 4. Female university students participated in Experiments 2 and 3, whereas unemployed loweducated women participated in both Experiments 1 and 4. Finally, we used different tasks in Experiment 3 from those that were used in Experiments 1, 2, and 4. Our results were thus replicated through different paradigms, different instructions, and different populations.

Taken together, our four experiments suggested that benevolent sexism involved communication of detrimental thoughts. Under the cover of inoffensive introductory remarks, benevolent sexism created a mindset of preoccupation, self-doubt (including some anxiety), and decreased self-esteem. Such mental intrusions then interfered with the task to be performed and undermined performance, despite the fact that the context valued feminine skills. On the contrary, hostile sexism sounded and actually was more aggressive. It was detected as prejudice and therefore left no ambiguity, thereby facilitating external attribution or blame; hostile sexism did not impair the women's performance.

Extending Vescio et al.'s (2005) work, we distinguished between the hostile and benevolent components of sexism that were involved in patronizing behavior and showed their respective impacts on both motivation to perform and interfering thoughts, two processes that could have been thought to influence women's performance. In addition, we clearly identified mental intrusions as 
the process through which performance was damaged, and we shed light on how gender identification partially protected against sexist attitudes.

Clearly, benevolent statements conveyed some negative ideas about women, who were suggested to be cooperative and warm but in need of men's help, and thus relatively incompetent. On the other hand, hostile sexism suggested that women are uncooperative and cold, but independent, mean, and assertive. As argued by Fiske and her colleagues (e.g., Fiske, Cuddy, Glick, \& Xu, 2002), many stereotypes are mixed in their evaluative content, but perceptions of warmth and competence of social groups are often inversely related to one another (Judd, James-Hawkins, Yzerbyt, \& Kashima, 2005). That is, focusing on a group's warmth implicitly communicated low competence inferences about that group. Once activated, stereotypes may influence people's automatic behavior and nonconscious goal pursuit (see Dijksterhuis \& Bargh, 2001; Wheeler \& Petty, 2001). By focusing on women's warmth, benevolent sexism could thus subtly activate the idea of women's low competence and lead them to behave consistently. Importantly, implicit activation of women's alleged incompetence, in conjunction with the difficulty of making external attributions for the statements, likely led benevolent sexism to be perceived by women as unpleasant and to evoke intrusive thoughts and anxiety or self-doubt about their competence.

In our experiments, we examined both performance and the number of items attempted. In our view, performance was perhaps the most relevant index of women's actual competence and surely the one having the greatest consequences in real life. In most evaluative situations, it is the total number of correct answers that counts. Employers usually look at the absolute score one receives on selection tasks to decide whether to select a candidate. In all four experiments, performance was impaired by benevolent more than by hostile sexism. Even if taken into account, the number of items attempted by participants had fewer implications for real-life situations than did global performance. This measure nevertheless revealed other aspects that could be affected when confronting sexism. In Experiments 1 and 2, many trials were attempted, and ceiling effects did not allow us to observe the impact of sexism on that measure. However, Experiment 4 revealed that fewer trials were attempted when women faced benevolent rather than hostile sexism. This suggests that mental intrusions might (but not necessarily) have affected both performance and the number of items attempted by interfering with concentration and slowing down performance on the required task. Indeed, the role of mental intrusions on both these effects had been confirmed by our mediation analyses.

Recent research on stigmatization has shown that the negative effect of stigma on performance could be due to anxiety and decrements in working memory (e.g., Schmader \& Johns, 2003). We suggest that benevolent sexism was a way of stigmatizing women that interfered with performance by reducing working memory capacity in contexts in which we would not expect women to feel incompetent. By triggering numerous mental intrusions, such as self-doubt or preoccupation including anxiety and reduced self-esteem, benevolent sexism lowered performance and impaired cognitive capacity that would normally be devoted to the task at hand. The content it activates and the difficulty of making external attributions for the negative ideas suggested about women make benevolent sexism a dangerous tool that might be used by men to maintain power over women.

Osborne (2001); Spencer, Steele, and Quinn (1999); and Bosson, Haymovitz, and Pinel (2004), among a few others, have found initial support for the idea that anxiety contributes to stereotype threat (i.e., fear of confirming the negative stereotype associated with the ingroup, resulting in stereotype confirmation). Close to the concept of anxiety, arousal has also been found to play an important role in the deleterious effects of stereotype threat (e.g., Ben-Zeev, Fein, \& Inzlicht, 2005; Blascovich, Spencer, Quinn, \& Steele, 2001; O'Brien \& Crandall, 2003). Along the same line, Schmader and Johns (2003) found that stereotype threat reduced women's performance on a mathematical test by diminishing their working memory capacity. Finally, Inzlicht, McKay, and Aronson (2006) recently showed that stigma was ego depleting and that trying to cope with it weakened the ability to control one's behavior in unrelated domains. When we paralleled our results with this literature, it appeared that benevolent sexism acted as a stereotype threat or a stigma within feminine domains and indeed had equivalent damaging consequences on women's performance. Also, benevolent sexism induced some anxiety, mixed with doubts about performance abilities. Although benevolent sexism might remind us of stereotype threat, we doubt that hostile sexism matched the classic control or nonthreatening conditions used in that literature. Indeed, in contrast to research on stereotype threat showing that highly identified individuals are more at risk of lowered performance (e.g., Schmader, 2002), our results indicated that, if anything, strongly identifying with the gender ingroup helped to preserve performance in the face of hostile sexism.

Several theories stress the role of benevolent stereotypes and "nice" ideologies in leading members of disadvantaged groups to justify the status quo. Our experiments went further and suggested that disadvantaged group members indeed behaviorally support the basis of existing gender inequality and system justifications. All these theories imply that, on some occasions, women are "accomplices" in their own subordination. Glick and Fiske (1996, 2001; Glick et al., 2000) have constantly argued that benevolent sexism and the "women are wonderful" effect documented by Eagly and Mladinic $(1989,1993)$ serve to increase support for the system of gender inequality. According to system justification theory (e.g., Jost \& Banaji, 1994), ambivalent sexism theory (e.g., Glick \& Fiske, 2001), and social dominance theory (e.g., Sidanius \& Pratto, 1999), stereotypes are legitimizing tools that help high-status groups keep low-status groups in the state of subordination. When stereotypes are behaviorally confirmed as in our experiments (women performed poorly), reality rather than stereotypes surely helps the legitimizing of status differentials. Following Jackman (1994) and Cose (1993), dominant groups prefer to act benevolently towards low-status groups, because the latter will more easily agree on their inferior status (Haines \& Jost, 2000; Rudman \& Heppen, 2003) and even support this hierarchical social system (Jost \& Kay, 2005). Considering the results of our experiments in this regard, we confirm the pertinence and appropriateness of dominant groups' preferences.

Our results are also perfectly consistent with a study by Jost and Kay (2005) recently demonstrating that women, but not men, are more prone to support the general and diffuse system of inequality after being exposed to benevolent stereotypes than in a comparably favorable but nonstereotypical control condition. Hostile stereo- 
types, on the contrary, did not lead women to increase system justification.

Similarly, our results nicely fit Jackman's (1994) velvet glove theory as well as Benokraitis's (1997) propositions about the effectiveness of "sweet" discrimination in maintaining gender status inequities. According to Karl Marx himself, it was soon recognized that legitimacy of dominance needed a state of "false consciousness" among subordinates. Along with Jost and Banaji's (1994) theory of system justification, Glick and Fiske's (2001) theory of benevolent and hostile sexism, and Sidanius and Pratto's (1999) theory of social dominance, Jackman's (1994, 2001) velvet glove theory holds that subordinates are often accomplices in their own subordination. Although the research on the psychology of legitimacy has provided numerous empirical investigations of this idea (see, e.g., Jost \& Hunyady, 2002; Jost \& Major, 2001), very few studies have provided direct experimental evidence of the "efficiency" of paternalistic and benevolent attitudes in maintaining inequalities compared with more overt and hostile ones. By providing evidence of their own incompetence, albeit fully contextual, women who confronted benevolent sexism in our experiments offered legitimizing arguments to men who might be willing to use them in justifying inequalities of the societal system.

In fact, although we do not wish to suggest that hostile sexism would have no negative effects in the long term, in the short term, exposure to explicit and hostile sexism was not that damaging. As we showed, hostile sexism preserved performance. Moreover, as we demonstrated, it was through mental intrusions that benevolent sexism was detrimental to women. Informing them of the dangers of accepting benevolent sexism may reduce uncertainties and help preserve performance. This would undoubtedly facilitate women's countering the effects that dominant groups might be seeking when using such an untrustworthy strategy.

To conclude, we provided strong and consistent evidence that benevolent sexism is a very efficient tool that can push women into providing the best justification for gender inequality. By "objectively" performing poorly, women facing benevolent sexism could indeed hardly contest their own (group) subordination. As outrageous as it is, hostile or blatant sexism may well paradoxically eventually serve women's cause. Further research is certainly needed to ascertain the whole range of influences sexism has on women's behavior and their implications for intergroup relationships. Although some influences may potentially be positive, we do not recommend men to be overtly sexist, because this may be damaging for women's self-esteem in the long run. Rather, we recommend that women and men not consider benevolent sexism to be benign.

\section{References}

Abrams, D., Viki, G. T., Masser, B., \& Bohner, G. (2003). Perceptions of stranger and acquaintance rape: The role of benevolent and hostile sexism in victim blame and rape proclivity. Journal of Personality and Social Psychology, 84, 111-125.

Bargh, J. A. (1997). The automaticity of everyday life. In R. S. Wyer, Jr. (Ed.), Advances in social cognition (Vol. 10, pp. 1-61). Mahwah, NJ: Erlbaum.

Baron, R. M., \& Kenny, D. A. (1986). The moderator-mediator distinction in social psychological research: Conceptual, strategic, and statistical considerations. Journal of Personality and Social Psychology, 51, 1173-1182.

Barreto, M., \& Ellemers, N. (2005). The burden of benevolent sexism:
How it contributes to the maintenance of gender inequalities. European Journal of Social Psychology, 35, 633-642.

Beilock, S. L., \& Carr, T. H. (2005). When high-powered people fail: Working memory and "choking under pressure" in math. Psychological Science, 16, 101-105.

Beilock, S. L., Kulp, C. A., Holt, L. E., \& Carr, T. H. (2004). More on the fragility of performance: Choking under pressure in mathematical problem solving. Journal of Experimental Psychology: General, 133, 584-600.

Benokraitis, N. V. (1997). Subtle sexism. Current practices and prospects for change. Thousand Oaks, CA: Sage.

Ben-Zeev, T., Fein, S., \& Inzlicht, M. (2005). Arousal and stereotype threat. Journal of Experimental Social Psychology, 41, 174-181.

Blascovich, J., Spencer, S. J., Quinn, D., \& Steele, C. (2001). African Americans and high blood pressure: The role of stereotype threat. Psychological Science, 12, 225-229.

Bosson, J. K., Haymovitz, E. L., \& Pinel, E. C. (2004). When saying and doing diverge: The effects of stereotype threat on self-reported versus non-verbal anxiety. Journal of Experimental Social Psychology, 40, 247-255.

Branscombe, N. R., Schmitt, M. T., \& Harvey, R. D. (1999). Perceiving pervasive discrimination among African-Americans: Implications for group identification and well-being. Journal of Personality and Social Psychology, 77, 135-149.

Brauer, M. (2002). The analysis of continuous and categorical independent variables: Alternatives to dichotomization. L'Année Psychologique, 102, 449-484.

Brehm, J. (1966). A theory of psychological reactance. New York: Academic Press.

Brehm, J., \& Weintraub, M. (1977). Physical barriers and psychological reactance: 2-year-olds' response to threats to freedom. Journal of Personality and Social Psychology, 35, 830-836.

Chen, M., \& Bargh, J. A. (1997). Nonconscious behavioral confirmation processes: The self-fulfilling nature of automatically activated stereotypes. Journal of Experimental Social Psychology, 33, 541-560.

Cohen, J. (1983). The cost of dichotomization. Applied Psychological Measurement, 7, 249-253.

Cose, E. (1993). Rage as a privileged class. New York: HarperCollins.

Crocker, J., \& Major, B. (1989). Social stigma and self-esteem: The self-protective properties of stigma. Psychological Review, 96, 608 630.

Crocker, J., Voelk1, K., Testa, M., \& Major, B. (1991). Social stigma: The affective consequences of attributional ambiguity. Journal of Personality and Social Psychology, 60, 218-228.

Daneman, M., \& Carpenter, P. A. (1980). Individual differences in working memory and reading. Journal of Verbal Learning and Verbal Behavior, 19, 450-466.

Daneman, M., \& Merikle, P. M. (1996). Working memory and language comprehension: A meta-analysis. Psychonomic Bulletin and Review, 3 , 422-433.

Dardenne, B., Delacollette, N., Grégoire, C., \& Lecocq, D. (2006). Latent structure of the French validation of the Ambivalent Sexism Inventory: L'Echelle de Sexisme Ambivalent. L'Année Psychologique, 106, 235-264.

Dijksterhuis, A., Aarts, H., Bargh, J. A., \& van Knippenberg, A. (2000). Past contact, stereotype strength, and automatic behavior. Journal of Experimental Social Psychology, 36, 531-544.

Dijksterhuis, A., \& Bargh, J. A. (2001). The perception-behavior expressway: Automatic effects of social perception on social behavior. In M. P. Zanna (Ed.), Advances in Experimental Social Psychology (Vol. 33, pp. 1-40). San Diego, CA: Academic Press.

Dijksterhuis, A., \& van Knippenberg, A. (1998). The relation between perception and behavior, or how to win a game of trivial pursuit. Journal of Personality and Social Psychology, 74, 865-877.

Eagly, A. H., \& Mladinic, A. (1989). Gender stereotypes and attitudes 
toward women and men. Personality and Social Psychology Bulletin, 15, 543-558.

Eagly, A. H., \& Mladinic, A. (1993). Are people prejudiced against women? Some answers from research an attitudes, gender stereotypes, and judgment of competence. In W. Stroebe \& M. Hewstone (Eds.), European Review of Social Psychology (Vol. 5, pp. 1-35). New York: Wiley.

Engle, R. W. (2001). What is working memory capacity? In H. L. Roediger III \& J. S. Nairne (Eds.), The nature of remembering: Essays in honor of Robert G. Crowder (pp. 297-314). Washington, DC: American Psychological Association.

Engle, R. W., Tuholski, S. W., Laughlin, J. E., \& Conway, A. R. A. (1999). Working memory, short-term memory, and general fluid intelligence: A latent variable approach. Journal of Experimental Psychology: General, 128, 309-331.

Fiske, S. T., Cuddy, A. J. C., Glick, P., \& Xu, J. (2002). A model of (often mixed) stereotype content: Competence and warmth respectively follow from perceived status and competition. Journal of Personality and Social Psychology, 82, 878-902.

Ford, T. E., Wentzel, E. R., \& Lorion, J. (2001). Effects of exposure to sexist humor on perceptions of normative tolerance of sexism. European Journal of Social Psychology, 31, 677-691.

Frijda, N. H., Kuipers, P., \& ter Schure, E. (1989). Relations among emotion, appraisal, and emotional action readiness. Journal of Personality and Social Psychology, 57, 212-228.

Glick, P., \& Fiske, S. T. (1996). The Ambivalent Sexism Inventory: Differentiating hostile and benevolent sexism. Journal of Personality and Social Psychology, 70, 491-512.

Glick, P., \& Fiske, S. T. (2001). An ambivalent alliance: Hostile and benevolent sexism as complementary justifications for gender inequality. American Psychologist, 56, 109-118.

Glick, P., Fiske, S. T., Mladinic, A., Saiz, J., Abrams, D., Masser, B., et al. (2000). Beyond prejudice as simple antipathy: Hostile and benevolent sexism across cultures. Journal of Personality and Social Psychology, 79, 763-775.

Haines, E. L., \& Jost, J. T. (2000). Placating the powerless: Effects of legitimate and illegitimate explanation on affect, memory, and stereotyping. Social Justice Research, 13, 219-236.

Harmon-Jones, E., Sigelman, J. D., Bohling, A., \& Harmon-Jones, C. (2003). Anger, coping, and frontal cortical activity: The effect of coping potential on anger-induced left frontal activity. Cognition and Emotion, 17, 1-24.

Heatherton, T. F., \& Polivy, J. (1991). Development and validation of a scale measuring state self-esteem. Journal of Personality and Social Psychology, 60, 895-910.

Heilman, M. E., \& Alcott, V. B. (2001). What I think you think of me: Women's reactions to being viewed as beneficiaries of preferential selection. Journal of Applied Psychology, 86, 574-582.

Inzlicht, M., McKay, L., \& Aronson, J. (2006). Stigma as ego depletion. Psychological Science, 17, 262-269.

Jackman, M. (1994). The velvet glove: Paternalism and conflict in gender, class and race relations. Berkeley: University of California Press.

Jackman, M. (2001). License to kill: Violence and legitimacy in expropriative social relations. In J. T. Jost \& B. Major (Eds.), The psychology of legitimacy: Emerging perspectives on ideology, justice, and intergroup relations. Cambridge, England: Cambridge University Press.

Jost, J. T., \& Banaji, M. (1994). The role of stereotyping in system justification and the production of false consciousness. British Journal of Social Psychology, 22, 1-27.

Jost, J. T., \& Hunyady, O. (2002). The psychology of system justification and the palliative function of ideology. In W. Stroebe \& M. Hewstone (Eds.), European Review of Social Psychology (Vol. 13, pp. 111-153). New York: Wiley.

Jost, J. T., \& Kay, A. C. (2005). Exposure to benevolent sexism and complementary gender stereotypes: Consequences for specific and dif- fuse forms of system justification. Journal of Personality and Social Psychology, 88, 498-509.

Jost, J. T., \& Major, B. (2001). The psychology of legitimacy. Emerging perspectives on ideology, justice, and intergroup relations. Cambridge, England: Cambridge University Press.

Judd, C. M. (2000). Everyday data analysis in social psychology: Comparisons of linear models. In H. T. Reis \& C. M. Judd (Eds.), Handbook of research methods in social and personality psychology (pp. 370392). Cambridge, England: Cambridge University Press.

Judd, C. M., James-Hawkins, L., Yzerbyt, V., \& Kashima, Y. (2005). Fundamental dimensions of social judgment: Understanding the relations between judgments of competence and warmth. Journal of Personality and Social Psychology, 89, 899-913.

Just, M. A., \& Carpenter, P. A. (1992). A capacity theory of comprehension: Individual differences in working memory. Psychological Review, 103, 761-772.

Kaiser, C. R., \& Miller, C. T. (2001). Reacting to impending discrimination: Compensation for prejudice and attributions to discrimination. Personality and Social Psychology Bulletin, 27, 1357-1367.

Major, B., McCoy, S. K., Kaiser, C. R., \& Quinton, W. J. (2003). Prejudice and self-esteem: A transactional model. In W. Stroebe \& M. Hewstone (Eds.), European Review of Social Psychology (Vol. 14, pp. 77-104). New York: Wiley.

Major, B., Quinton, W. J., \& Schmader, T. (2003). Attributions to discrimination and self-esteem: Impact of group identification and situational ambiguity. Journal of Experimental Social Psychology, 39, 220-231.

McCoy, S. K., \& Major, B. (2003). Group identification moderates emotional responses to perceived prejudice. Personality and Social Psychology Bulletin, 29, 1005-1117.

Nadler, A., \& Fisher, J. D. (1986). The role of threat to self-esteem and perceived control in recipient reaction to help: Theory development and empirical validation. In L. Berkowitz (Ed.), Advances in experimental social psychology (Vol. 19, pp. 81-122). San Diego, CA: Academic Press.

O'Brien, L. T., \& Crandall, C. S. (2003). Stereotype threat and arousal: Effects on women's math performance. Personality and Social Psychology Bulletin, 29, 782-789.

Operario, D., \& Fiske, S. T. (2001). Ethnic identity moderates perceptions of prejudice: Judgments of personal versus group discrimination and subtle versus blatant bias. Personality and Social Psychology Bulletin, $27,550-561$.

Osborne, J. W. (2001). Testing stereotype threat: Does anxiety explain race and sex differences in achievement? Contemporary Educational Psychology, 26, 291-310.

Rosen, V. M., \& Engle, R. W. (1998). Working memory capacity and suppression. Journal of Memory and Language, 39, 418-436.

Rudman, L. A., \& Heppen, J. B. (2003). Implicit romantic fantasies and women's interest in personal power: A glass slipper effect? Personality and Social Psychology Bulletin, 29, 1357-1370.

Sakalli, U., \& Glick, P. (2003). Ambivalent sexism and attitudes toward women who engage in premarital sex in Turkey. Journal of Sex Research, 40, 296-302.

Scherer, K. R. (1988). Criteria for emotion-antecedent appraisal: A review. In V. Hamilton, G. H. Bower, \& N. H. Frijda (Eds.), Cognitive perspectives on emotion and motivation (pp. 89-126). Norwell, MA: Kluwer Academic.

Schmader, T. (2002). Gender identification moderates stereotype threat effects on women's math performance. Journal of Experimental Social Psychology, 38, 194-201.

Schmader, T., \& Johns, M. (2003). Converging evidence that stereotype threat reduces working memory. Journal of Personality and Social Psychology, 84, 440-452. 
Schmitt, M. T., Branscombe, N. R., Kobrynowicz, D., \& Owen, S. (2002). Perceiving discrimination against one's gender group has different implications for well-being in women and men. Personality and Social Psychology Bulletin, 28, 197-210.

Schneider, M. E., Major, B., Luhtanen, R., \& Crocker, J. (1996). When help hurts: Social stigma and the cost of assumptive help. Personality and Social Psychology Bulletin, 22, 201-209.

Sidanius, J., \& Pratto, F. (1999). Social dominance: An intergroup theory of social hierarchy and oppression. Cambridge, England: Cambridge University Press.

Smith, C. A., \& Ellsworth, P. C. (1985). Patterns of cognitive appraisal in emotion. Journal of Personality and Social Psychology, 48, 813838.

Spencer, S., Steele, C. M., \& Quinn, D. M. (1999). Stereotype threat and women's math performance. Journal of Experimental Social Psychology, 35, 4-28.

Stangor, C., Swim, J. K., Sechrist, G. B., DeCoster, J., Van Allen, K. L., \& Ottenbreit, A. (2003). Ask, answer, and announce: Three stages in perceiving and responding to discrimination. In W. Stroebe \& M. Hewstone (Eds.), European review of social psychology (Vol. 14, pp. 277311). New York: Wiley.
Turner, M. E., \& Pratkanis, A. R. (1994). Affirmative action as help: A review of recipient reactions to preferential selection and affirmative action. Basic and Applied Social Psychology, 15, 43-69.

Vescio, T. K., Gervais, S. J., Snyder, M., \& Hoover, A. (2005). Power and the creation of patronizing environments: The stereotype-based behaviors of the powerful and their effects on female performance in masculine domains. Journal of Personality and Social Psychology, 88, 658-672.

Viki, G. T., \& Abrams, D. (2003). Infra-humanization: Ambivalent sexism and the attribution of primary and secondary emotions to women. Journal of Experimental Social Psychology, 39, 492-499.

Wheeler, S. C., \& Petty, R. E. (2001). The effects of stereotype activation on behavior: A review of possible mechanisms. Psychological Bulletin, 127, 797-826.

Whitney, P., Arnett, P. A., Driver, A., \& Budd, D. (2001). Measuring central executive functioning: What's in a reading span? Brain and Cognition, 45, 1-14.

Received September 27, 2005 Revision received March 14, 2007 Accepted March 22, 2007

\section{New Editors Appointed, 2009-2014}

The Publications and Communications Board of the American Psychological Association announces the appointment of six new editors for 6-year terms beginning in 2009. As of January 1, 2008, manuscripts should be directed as follows:

- Journal of Applied Psychology (http://www.apa.org/journals/apl), Steve W. J. Kozlowski, PhD, Department of Psychology, Michigan State University, East Lansing, MI 48824.

- Journal of Educational Psychology (http://www.apa.org/journals/edu), Arthur C. Graesser, PhD, Department of Psychology, University of Memphis, 202 Psychology Building, Memphis, TN 38152.

- Journal of Personality and Social Psychology: Interpersonal Relations and Group Processes (http://www.apa.org/journals/psp), Jeffry A. Simpson, PhD, Department of Psychology, University of Minnesota, 75 East River Road, N394 Elliott Hall, Minneapolis, MN 55455.

- Psychology of Addictive Behaviors (http://www.apa.org/journals/adb), Stephen A. Maisto, PhD, Department of Psychology, Syracuse University, Syracuse, NY 13244.

- Behavioral Neuroscience (http://www.apa.org/journals/bne), Mark S. Blumberg, PhD, Department of Psychology, University of Iowa, E11 Seashore Hall, Iowa City, IA 52242.

- Psychological Bulletin (http://www.apa.org/journals/bul), Stephen P. Hinshaw, PhD, Department of Psychology, University of California, Tolman Hall \#1650, Berkeley, CA 94720. (Manuscripts will not be directed to Dr. Hinshaw until July 1, 2008, as Harris Cooper will continue as editor until June 30, 2008.)

Electronic manuscript submission: As of January 1, 2008, manuscripts should be submitted electronically via the journal's Manuscript Submission Portal (see the website listed above with each journal title).

Manuscript submission patterns make the precise date of completion of the 2008 volumes uncertain. Current editors, Sheldon Zedeck, PhD, Karen R. Harris, EdD, John F. Dovidio, PhD, Howard J. Shaffer, PhD, and John F. Disterhoft, PhD, will receive and consider manuscripts through December 31, 2007. Harris Cooper, PhD, will continue to receive manuscripts until June 30, 2008. Should 2008 volumes be completed before that date, manuscripts will be redirected to the new editors for consideration in 2009 volumes. 